\title{
Synthesis, Structural Studies on Ni-Zn Ferrite by Solid State Reaction Method
}

\author{
G.PAVAN KUMAR $^{1 *}$ VEMURI RAGHAVENDRA $^{2}$ and CH.PRAVEEN BABU ${ }^{3}$ \\ ${ }^{1}$ Advanced Analytical Laboratory, Andhra University, Visakhapatnam, India \\ ${ }^{2}$ Department of Engineering Physics, AUCE (A), Andhra University, India \\ ${ }^{3}$ Department of Physics, Andhra University, Visakhapatnam, India \\ pavan.phy@gmail.com
}

Received 11 August 2016 / Accepted 3 September 2016

\begin{abstract}
Ni}_{\mathrm{x}} \mathrm{Zn}_{1-\mathrm{x}} \mathrm{Fe}_{2} \mathrm{O}_{4}(\mathrm{x}=0.50)$ have been synthesized by solid state reaction technique. X-ray powder diffraction patterns revealed that the single-phase cubic structure. The observations reflections are (220), (311), (222), (400), (422), (511) and (440). The average particle size is $40 \mathrm{~nm}$. The lattice constant is $8.3715 \AA$ A. SEM analysis reveals detailed information about ceramic surface texture, grain sizes and shapes and grain boundaries. The average grain size is found to be $0.54 \mu \mathrm{m}$.
\end{abstract}

Keywords: Ni-Zn, Solid State, Spinel, SEM, X-Ray diffraction

\section{Introduction}

Ferrites usually have the combination of iron $(\mathrm{Fe})$ oxides with oxides. Ferrites have wide range of technological applications depending upon their properties like curie-temperature, micro-structure, density, grain size, saturation magentisation. To get good potential applications from ferrite material depend upon starting materials, stiochiometry, sintering temperature, chemical homogeneity. Solid state reaction is one of the vital method for large scale industrial applications. $\mathrm{AB}_{2} \mathrm{O}_{4}$ type of compounds with spinal structure shows interesting structural, electrical and magnetic properties, which vary with the nature of the ions, their charge and site distribution amongst tetrahedral and octahedral sites. Various cations can be placed in A site and B site to tune its magnetic properties. Depending on A site and $\mathrm{B}$ site cations it can exhibit ferromagnetic, anti ferromagnetic, spin and paramagnetic behavior $\mathrm{Ni}-\mathrm{Zn}$ ferrites are one of the most prominent magnetic materials which have many useful technological applications such as a power transformers, antennas, digital tapes, sensor applications. Ni-Zn ferrites having permeability, high resistivity, low dielectric losses, mechanical hardness and chemical stability ${ }^{1,2}$. The Ni-Zn ferrites have initial permeability in the range of 10 to 1000 , decreasing with $\mathrm{Ni}$ content. Coercivity is in several Oersteds and resistivity is very high, $10^{5}$ to $10^{6} \mathrm{ohm}-\mathrm{cm}$. The Ni-Zn ferrites have been produced by the conventional method which commercially involves both long and high 
temperature treatments for the oxides used in their preparation ${ }^{3,4}$. In this paper we report synthesis, structural properties of $\mathrm{Ni}-\mathrm{Zn}$ ferrites by solid state reaction method.

\section{Experimental}

$\mathrm{Ni}-\mathrm{Zn}$ ferrite particles are mainly depending upon the synthesis process. $\mathrm{Ni}_{\mathrm{x}} \mathrm{Zn}_{1-\mathrm{x}} \mathrm{Fe}_{2} \mathrm{O}_{4}$ $(x=0.50)$ were prepared by solid state reaction method ${ }^{5,6}$. All analar grade nickel oxide $(\mathrm{NiO})$, zinc oxide $(\mathrm{ZnO})$, ferric oxide $\left(\mathrm{Fe}_{2} \mathrm{O}_{3}\right)$ were weighed according to stoichiometric proportion. To form a homogenous mixture, it was carried out by using agate mortar in acetone medium. The slurry was placed in crucible and calcined at $950{ }^{\circ} \mathrm{C}$ for $2-3$ hours. The calcined powders again grounded. It results in better homogenization of the sample. The samples send to X-ray diffraction (Pan Alytical, X-Pert pro, Netherland) to know the structure and particle size of the sample and the sample were scanned in the range $10-80^{\circ}$. At this stage, the sample were mixed with 5\% PVA used as binder and pressed in to pellets by applying pressure of $5 \mathrm{ton} / \mathrm{cm}^{2}$. The pellets were finally sintered in air at $1050{ }^{\circ} \mathrm{C}$ to $1100{ }^{\circ} \mathrm{C}$ for 4 hours to complete the process. The flow chart for solid state reaction method is given Figure 1. Scanning electron micrographs of sintered coated pellets were obtained using JSM-6610LV, JEOL Asia PTE Ltd, Japan. $X$-Ray diffraction and SEM instruments.

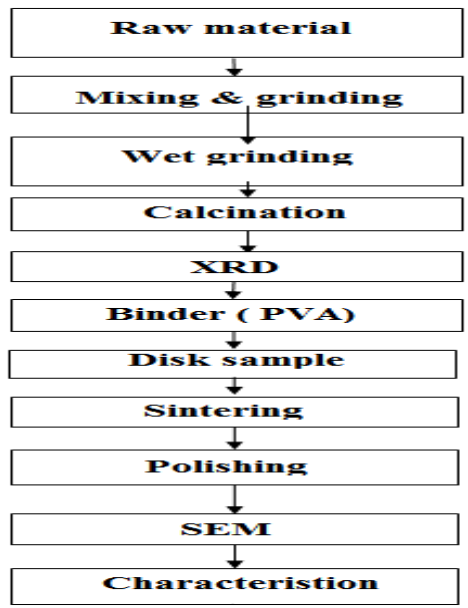

Figure 1. Flow chart for solid state reaction method

\section{Results and Discussion}

\section{Crystallite size calculation}

The scherer formula ${ }^{7}$ relates the thickness of the crystallite to the width of its diffraction peaks and is widely used to determine particle size in ceramics, clays and polymers. The Scherrer formula is given by:

$$
\mathrm{D}=(\mathrm{k} \lambda) /\left(\beta \cos \theta_{\mathrm{B}}\right) .
$$

Where, $D$ is the crystallite thickness, $\beta$ is the broadening of diffraction line measured at half its maximum intensity, $\mathrm{k}$ is the shape factor and $\lambda$ is the wavelength of the $\mathrm{x}$-ray beam.

\section{$X$-Ray diffraction studies}

The XRD patterns of the composition $\mathrm{Ni}_{\mathrm{x}} \mathrm{Zn}_{1-\mathrm{x}} \mathrm{Fe}_{2} \mathrm{O}_{4}(\mathrm{x}=0.50)$ are shown in Figure $2 \&$ Table 1. The analysis of $\mathrm{x}$-ray powder diffraction patterns revealed that the single-phase cubic structure. The reflections in the figure are well matched with spinel structure. The observations 
reflections are (220) (311), (222), (400) (422) (511) and (440) 311 peak is more intensive when compared to other peaks. These are well matched with reported values ${ }^{8}$. The average particle size is $40 \mathrm{~nm}$.

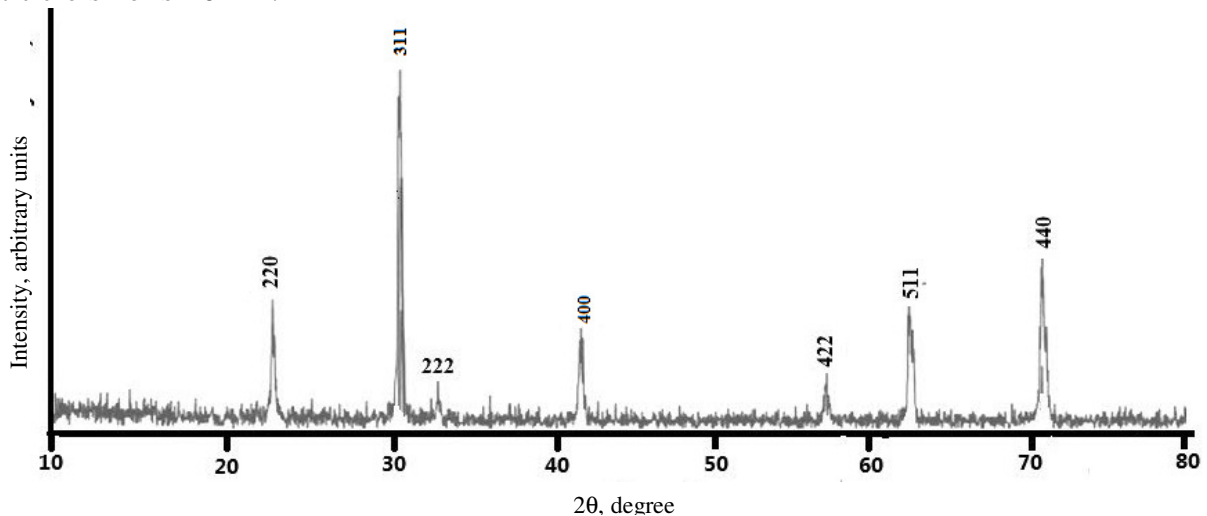

Figure 2. $\mathrm{X}$-ray diffraction patterns for $\mathrm{Ni}_{\mathrm{x}} \mathrm{Zn}_{1-\mathrm{x}} \mathrm{Fe}_{2} \mathrm{O}_{4}(\mathrm{x}=0.50)$

Tabel 1. $X$-Ray diffraction data

\begin{tabular}{ccccc}
\hline Composition & $\begin{array}{c}\text { Lattice constant } \\
(\AA)\end{array}$ & $\begin{array}{c}\text { Bragg angle } \\
2 \theta \text {, degree }\end{array}$ & $\begin{array}{c}\text { Particle size, } \\
\mathrm{nm}\end{array}$ & $\begin{array}{c}\text { Grain size, } \\
\mu \mathrm{m}\end{array}$ \\
\hline $\mathrm{Ni}_{0.5} \mathrm{Zn}_{0.5} \mathrm{Fe}_{2} \mathrm{O}_{4}$ & $8.3715 \mathrm{~A}^{\mathrm{o}}$ & 35.843 & 40 & 0.54 \\
\hline
\end{tabular}

\section{SEM studies}

Scanning electron micrographs of sintered coated pellets were obtained using (JSM-6610LV, Jeol Asia PTE Ltd, Japan). Scanning electron microscope (SEM) is a powerful tool for unveiling important and useful information about the microstructure of solids. Average grain size in each of the specimen has been calculated by line intercept method ${ }^{9}$. SEM analysis reveals detailed information about ceramic surface texture, grain sizes and shapes and grain boundaries. From the micrographs it is observed that the grains are spherical in shape smaller in size and no exaggerated grain growth has taken place in the sample during sintering. The grain boundaries act as a source of resistance. The grain boundaries act as sinks for impurities and preferred sites for nucleation of inclusions. The average grain size is found to be $0.54 \mu \mathrm{m}$ from Figure 3. A small grain size is also valuable since it leads small domain spacing, small grain size is quite important for technical purposes especially for the high frequency materials.

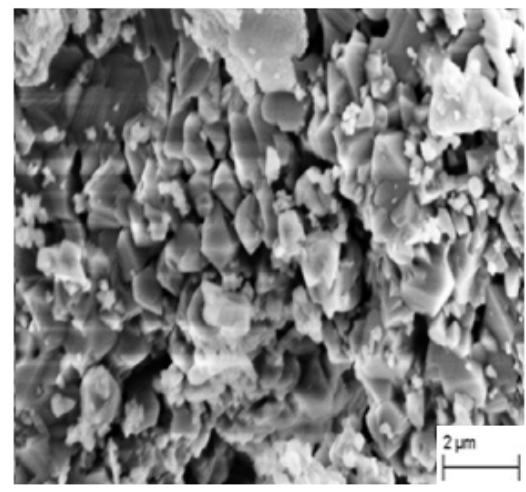

Figure 3. $\mathrm{SEM}$ of $\mathrm{Ni}_{0.5} \mathrm{Zn}_{0.5} \mathrm{Fe}_{2} \mathrm{O}_{4}$ 


\section{Conclusion}

$\mathrm{Ni}_{\mathrm{x}} \mathrm{Zn}_{1-\mathrm{x}} \mathrm{Fe}_{2} \mathrm{O}_{4}(\mathrm{x}=0.50)$ have been synthesized by solid state reaction technique. X-Ray powder diffraction patterns revealed that the single-phase cubic structure. The observations reflections are (220) (311), (222), (400) (422) (511) and (440). The average particle size is $40 \mathrm{~nm}$. The lattice constant is $8.3715 \AA$. The average grain size is found to be $0.54 \mu \mathrm{m}$. A small grain size is quite important for technical purposes especially for the high frequency materials.

\section{References}

1. Rosales M I, Amano E, Cuautle M P and Valenzuela R, Mater Sci Eng B, 1997, 49(3), 221-226; DOI:10.1016/S0921-5107(97)00139-6

2. Zahi S, Daud A R and Hashim M, Mater Chem Phys., 2007, 106(2-3), 452-456; DOI:10.1016/j.matchemphys.2007.06.031

3. Akther Hossain A K M, Seki M, Kawai T and Tabata H, J Appl Phys., 2004, 96(2), 1273; DOI:10.1063/1.1762707

4. Goldman A, Handbook of Modern Ferromagnetic Materials, Kulwer Academic Publishers, Boston, USA, 1999.

5. Gupta R G and Mendiratha R G, J Appl Phys., 1997a, 48(7), 2998-3000.

6. Gupta R G and Mendiratha R G, J Appl Phys., 1997b, 48(2), 845-848.

7. Cullity B D and Stock S R, Elements of X-ray Diffraction, $3^{\text {rd }}$ Edition, Prentice Hall, Upper Saddle River, NJ, 2001.

8. Johnson M T and Visser E G, IEEE Tans Magnetics, 1990, 26(5), 1987-1989.

9. Takenaka T, Maruyama K and Sakata K, Jpn J Appl Phys., 1991, 30(9B), 2236-2239; DOI:10.1143/JJAP.30.2236 